\title{
A Multicenter Cohort Study for XELOX (Capecitabine, Leucovorin plus Oxaliplatin) Therapy as First-Line Treatment in Elderly Patients with Unresectable Colorectal Cancer
}

\author{
Tetsu Yamamoto ${ }^{*}$, Ryoji Hyakudomi' ${ }^{1}$, Shinichi Sugimoto ${ }^{2}$, Atsuo Tokuka², \\ Yoshitoshi Sato $^{3}$, Satoshi Nagai ${ }^{4}$, Hikota Hayashi', Masahikoo Igarashi' ${ }^{5}$, Kenji Takubo3, \\ Yoshitsugu Tajima ${ }^{1}$ \\ ${ }^{1}$ Department of Digestive and General Surgery, Faculty of Medicine, Shimane University, Izumo, Japan \\ ${ }^{2}$ Department of Surgery, Shimane Prefectural Central Hospital, Izumo, Japan \\ ${ }^{3}$ Department of Gastroenterological Surgery, Matsue Red Cross Hospital, Matsue, Japan \\ ${ }^{4}$ Department of Surgery, National Hospital Organization Hamada Medical Center, Hamada, Japan \\ ${ }^{5}$ Department of Surgery, Masuda Medical Association Hospital, Masuda, Japan \\ Email: ${ }^{*}$ t2t2@med.shimane-u.ac.jp
}

Received 31 December 2014; accepted 3 February 2015; published 4 February 2015

Copyright (C) 2015 by authors and Scientific Research Publishing Inc.

This work is licensed under the Creative Commons Attribution International License (CC BY).

http://creativecommons.org/licenses/by/4.0/

(c) (i) Open Access

\section{Abstract}

Oxaliplatin-based chemotherapy with bevacizumab is now widely used for colorectal cancer patients. This study evaluated the efficacy and tolerability of XELOX (capecitabine + oxaliplatin + leucovorin combined) therapy with or without bevacizumab in elderly patients. One hundred and seven patients, consisting of 52 elderly ( $>70$ years of age) and 55 non-elderly, with unresectable colorectal cancer were enrolled in this multicenter cooperative group study using a database between October 2009 and March 2012. We evaluated the outcomes in terms of the median time to treat failure (TTF), overall response rate (ORR), disease control rate (DCR) and tolerability in both age groups. The median TTF for the XELOX + bevacizumab regimen was 7.1 months in the non-elderly group and 8.1 months in the elderly group $(p=0.838)$. There was no significant difference in TTF between the two groups. The ORR and DCR in the non-elderly group were $30.8 \%$ and $73.1 \%$, respectively. In the elderly group, the ORR was $40.0 \%$ and the overall DCR was $90.0 \%$. No severe or uncontrollable adverse events were observed in the two groups. These data indicated that the XELOX chemotherapy with or without bevacizumab has an equivalent efficacy in both groups, without increasing the adverse events even in the elderly population.

"Corresponding author.

How to cite this paper: Yamamoto, T., et al. (2015) A Multicenter Cohort Study for XELOX (Capecitabine, Leucovorin plus Oxaliplatin) Therapy as First-Line Treatment in Elderly Patients with Unresectable Colorectal Cancer. Journal of Cancer Therapy, 6, 153-162. http://dx.doi.org/10.4236/jct.2015.62017 


\section{Keywords}

\section{Colorectal Cancer, Oxaliplatin, Capecitabine, Bevacizumab, Elderly Patients}

\section{Introduction}

Colorectal cancer (CRC) is one of the most common forms of cancer worldwide. The annual incidence of CRC increases considerably with age. There are several chemotherapy combinations with proven activity in unresectable CRC. Nevertheless, there is a fear of great susceptibility to severe adverse events in elderly patients due to limitations in the functional reserve of various organ systems associated with aging. Therefore, the number of elderly patients included in clinical trials remains limited.

Oxaliplatin, in combination with either 5-fluorouracil (5-FU) (FOLFOX) or capecitabine (XELOX), is now widely used in the treatment of CRC, both in the adjuvant and metastatic setting [1] [2]. In addition, the management of metastatic CRC has evolved substantially with the introduction of biologic agents. Bevacizumab, a recombinant humanized monoclonal antibody against vascular endothelial growth factor (VEGF), has produced clinically worthwhile improvements in efficacy [3]-[5]. Because oxaliplatin can lead to the development of specific cold-related dysesthesia and cumulative peripheral sensory neuropathy, many patients have to withdraw from oxaliplatin-containing regimens [6]. In addition, this neuropathy persists for a long time after the discontinuation of treatment. On the other hand, the primary adverse events associated with bevacizumab include thrombosis, hypertension, proteinuria and epistaxis. There are some reports that bevacizumab increases the risk of arterial thromboembolism (ATE) in patients with CRC or breast or lung cancer [7]. In addition, the risk of ATE is associated with a prior history of ATE and age (over 65 years).

There are many reports that elderly patients can receive the same regimens as non-elderly patient [8]-[10]. However, the population of elderly patients varies according to the locality. Furthermore, some reports have reported elderly patients to be underrepresented in clinical trials and less often treated according to the standard treatment [11] [12].

The Shimane Gastroenterological Cancer Study Group (SGCSG) has constructed a mutual database of patients with CRC in 2009 to survey the context of CRC treatment in Shimane prefecture, a rural region with quite a large elderly population in Japan, and then initiated several multicenter studies on the treatment of unresectable advanced/recurrent CRC. Since the impact of adding bevacizumab to doublet chemotherapy in elderly patients is unclear, we conducted a retrospective analysis of the efficacy and tolerability of XELOX with or without bevacizumab in elderly patients ( $\geq 70$ years of age) in a large elderly population area. And we chose a retrospective cohort study to evaluate the actual clinical situation in one prefecture.

\section{Patients and Methods}

\subsection{Study Population}

A sample survey of CRC patients receiving chemotherapy was conducted by using the SGCSG database recorded in the Microsoft Access 2007 software program (Microsoft Japan Co., Ltd., Tokyo, Japan). All colorectal cancer patients who undertook chemotherapy for advance/recurrent CRC in our region were enrolled in this database. Once a patient is enrolled in this database, the information of this patient is collected prospectively. Patients registered into the SGCSG database between October 2009 and March 2012 were extracted and enrolled in this study. The eligibility criteria in this study were as follows: histologically proven unresectable colorectal adenocarcinoma; a tumor lesion $>1 \mathrm{~cm}$ or non-measurable assessable lesion according to the response evaluation criteria in solid tumors (RECIST) on a computed tomography scan [13]; an adequate function of the liver, kidney and bone marrow reserve (absolute neutrophil count $>15,000 / \mathrm{L}$, hemoglobin $>8.5 \mathrm{~g} / \mathrm{dl}$, platelets $>100 \times$ $10^{9} / \mathrm{L}$ ); an Eastern Cooperative Oncology Group (ECOG) performance status (PS) of <2; an age $>20$ years at the time of starting first-line chemotherapy; and an expected survival time of $>3$ months. Patients with multiple malignancies, a history of prior radiotherapy, pregnancy or lactation, or a history of serious drug hypersensitivity were excluded from the analysis. Since there is a consensus that the elderly patient population is defined by an age of 70 years or older, we categorized the patients into two groups: $<70$ years of age (non-elderly patients) and $\geq 70$ years of age (elderly patients). 


\subsection{Treatment}

In this study, chemotherapy with XELOX +/- bevacizumab was performed at any line of treatment. An outline of the administration method for XELOX therapy is shown in Figure 1(a) and Figure 1(b). Briefly, the patients received a two-hour intravenous infusion of oxaliplatin at a dose of $130 \mathrm{mg} / \mathrm{m}^{2}$ on day 1 plus oral capecitabine at a dose of $1000 \mathrm{mg} / \mathrm{m}^{2}$ twice daily for two weeks every three weeks. Bevacizumab was administered at a dose of $7.5 \mathrm{mg} / \mathrm{kg}$ as a 30- to 90-minute intravenous infusion before the administration of oxaliplatin on Day 1.

The administration was continued until the patient showed progressive disease (PD), which included clinical PD or adverse events that made further administration difficult.

\subsection{Evaluation Procedure}

Before initiating chemotherapy, all patients were assessed using physical examinations, PS assessments and routine hematological and biochemical blood analyses. Computed tomography scans of measurable lesions were assessed within 28 days prior to the beginning of treatment and repeated every four cycles or three months. All adverse events were recorded before each cycle of chemotherapy. Toxicities were scored according to the Common Terminology Criteria for Adverse Events (CTCAE) v4.0 [14]. The primary assessment criterion was the time to treatment failure (TTF). The second criteria were the antitumor effects (ORR: overall response rate; and DCR: disease control rate) and safety in the elderly patients. The therapeutic efficacy was evaluated according to the RECIST guidelines (Version 1.1) [15].

\subsection{Statistical Analysis}

The chi-square test, Fisher's exact probability test and the Mann-Whitney U test were used to compare patient characteristics, treatment status, adverse events and antitumor effects. A probability (p) value of less than 0.05 was considered to be statistically significant for comparisons between the elderly and non-elderly groups. The Kaplan-Meier method was used to estimate the TTF. The statistical analyses were performed using the JMP ver. 9 software package (SAS institute Inc., Cary, NC).

(a) XELOX regimen

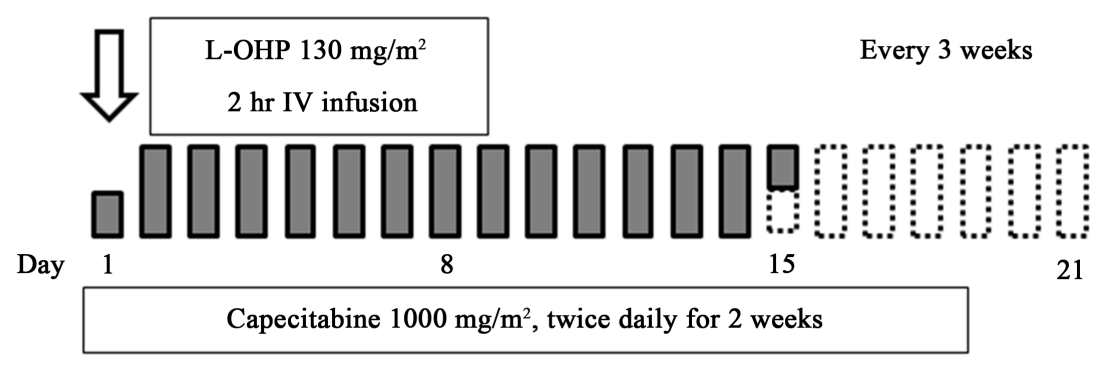

(b) XELOX + bevacizumab regimen

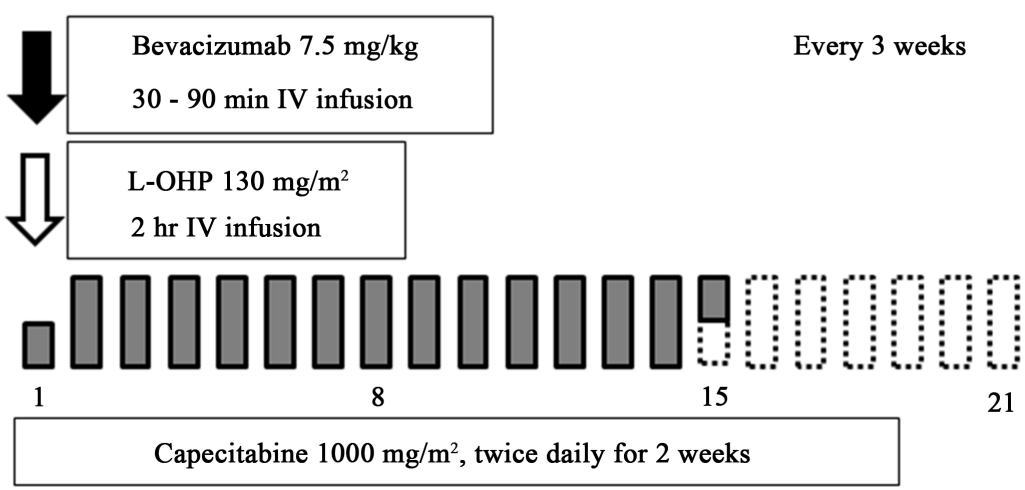

Figure 1. Chemotherapy regimens: (a) XELOX regimen; (b) XELOX + bevacizumab regimen. 


\section{Results}

\subsection{Patient Characteristics}

A total of 107 patients were enrolled in this study, consisting of 55 non-elderly patients who were $<70$ years of age and 52 elderly patients who were $\geq 70$ years of age. The median age was 69 years (range: 41 - 89); 61 years (range: 41 - 69) in the non-elderly group and 77 years (range: 70 - 89) in the elderly group. The baseline characteristics of the 107 eligible and treated patients are summarized in Table 1 . Thirty-nine patients (70.9\%) in the non-elderly group and 37 patients $(71.2 \%)$ in the elderly group were male. The patients generally had a widespread disease, with the most frequent sites for distant metastasis in the liver, lymph nodes, lungs and peritoneum. The performance status was less than 2 in almost all patients. Twenty-nine patients (52.7\%) in the nonelderly group and 29 patients (55.8\%) in the elderly group had colon cancer as the primary tumor. Seven patients (12.7\%) in the non-elderly group and 18 patients (34.6\%) in the elderly group received oral and/or venous administration of adjuvant chemotherapy prior to this study. There were no significant differences in the baseline characteristics between the two study groups.

\subsection{Treatment}

At the cutoff date (March 31, 2012), the median follow-up time for the entire group was 16.4 months. Seventynine patients (73.8\%) received XELOX with or without bevacizumab chemotherapy as first-line treatment, including 38 patients (69.2\%) in the non-elderly group and 41 patients (78.9\%) in the elderly group. As secondline chemotherapy, XELOX with or without bevacizumab treatment was performed in 13 patients (23.6\%) in the non-elderly group and five patients (9.6\%) in the elderly group.

\section{Table 1. Baseline characteristics of the two study groups.}

\begin{tabular}{|c|c|c|c|c|}
\hline & \multicolumn{2}{|c|}{$<70$ Years $(n=55)$} & \multicolumn{2}{|c|}{$\geq 70$ Years $(n=52)$} \\
\hline & $\mathrm{n}$ & $\%$ & $\mathrm{n}$ & $\%$ \\
\hline Age, y (median, range) & 61 & $(41-69)$ & 77 & $(70-89)$ \\
\hline Male & 39 & (70.9\%) & 37 & $(71.2 \%)$ \\
\hline Female & 16 & $(29.1 \%)$ & 15 & $(28.8 \%)$ \\
\hline \multicolumn{5}{|l|}{ PS (ECOG) } \\
\hline 0 & 53 & $(96.4 \%)$ & 44 & $(84.6 \%)$ \\
\hline 1 & 2 & $(3.6 \%)$ & 6 & $(11.5 \%)$ \\
\hline 2 & 0 & $(0.0 \%)$ & 2 & $(3.8 \%)$ \\
\hline \multicolumn{5}{|l|}{ Primary tumor } \\
\hline Colon & 29 & $(52.7 \%)$ & 29 & $(55.8 \%)$ \\
\hline Rectum & 26 & $(47.3 \%)$ & 23 & $(44.2 \%)$ \\
\hline \multicolumn{5}{|l|}{ Site of metastases } \\
\hline Liver & 25 & $(45.5 \%)$ & 24 & $(46.2 \%)$ \\
\hline Lymph nodes & 16 & (29.1\%) & 16 & $(30.8 \%)$ \\
\hline Lung & 12 & $(21.8 \%)$ & 9 & $(17.3 \%)$ \\
\hline Peritoneum & 5 & $(9.1 \%)$ & 10 & $(19.2 \%)$ \\
\hline Other & 5 & (9.1\%) & 4 & (7.7\%) \\
\hline Prior adjuvant chemotherapy & 7 & $(12.7 \%)$ & 18 & $(34.6 \%)$ \\
\hline
\end{tabular}

Abbreviations: PS, performance status; ECOG, Eastern Cooperative Oncology Group. Values in parentheses are percentages of row totals. 
Chemotherapy with XELOX + bevacizumab was performed in 78 patients $(72.9 \%)$, including 42 patients (76.4\%) in the non-elderly group and 36 patients (69.2\%) in the elderly group. Twenty-nine patients (27.1\%) received XELOX chemotherapy, including 13 patients (23.6\%) in the non-elderly group and 16 patients (30.8\%) in the elderly group. Non-elderly patients received a median of nine cycles (range, 1 - 30 cycles) of XELOX + bevacizumab regimen and a median of four cycles (range, 3 - 9 cycles) of XELOX regimen. On the other hand, elderly patients received a median of seven cycles (range, 1 - 27 cycles) of XELOX + bevacizumab regimen and a median of three cycles (range, 1 - 11 cycles) of XELOX regimen.

In the XELOX + bevacizumab treatment group, 25 patients received further chemotherapy after disease progression, including 12 patients (60.0\%) in the non-elderly group and 13 patients (81.3\%) in the elderly group. In the XELOX treatment group, 14 patients received further chemotherapy after disease progression, including eight patients (66.7\%) in the non-elderly group and six patients (60.0\%) in the elderly group.

\subsection{Efficacy}

Seventy-nine (73.8\%) of the 107 patients received XELOX with or without bevacizumab treatment as first-line chemotherapy. Fifty-eight (73.4\%) of these 79 patients were assessable for a response. Twenty-one patients, including 14 patients in the non-elderly group and seven patients in the elderly group, were not assessable. Thirteen patients ( 6 in the non-elderly group and 7 in the elderly group) were not assessable because the duration after the administration of chemotherapy did not exceed 28 days when the examination was performed.

In the XELOX + bevacizumab group, two (7.7\%) complete responses (CRs) and six (23.1\%) partial responses (PRs) were observed among the non-elderly patients (Table 2). On the other hand, one (5.0\%) CR and seven (35.0\%) PRs were observed among the elderly patients. In addition, 11 patients (42.3\%) in the non-elderly group and 10 patients $(50.0 \%)$ in the elderly group were revealed to have stable disease (SD). Therefore, the overall response rate (ORR; CR + PR) was $30.8 \%$ in the non-elderly group and $40.0 \%$ in the elderly group. The overall disease control rate (DCR; CR + PR + SD) was 73.1\% in the non-elderly group and $90.0 \%$ in the elderly group. There were no significant differences in the ORR $(p=0.839)$ and disease control rate DCR $(p=0.514)$ between the non-elderly and elderly groups.

When XELOX was performed as first-line chemotherapy, no CRs were observed in either the non-elderly or elderly groups. Three (15.8\%) PRs and seven (36.8\%) SDs were recorded in the non-elderly group. On the other hand, two (14.3\%) PRs and two (14.3\%) SDs were recognized in the elderly group. Therefore, the ORR was $15.8 \%$ and the DCR was $52.6 \%$ in the non-elderly group, while the ORR was $14.3 \%$ and the DCR was $28.6 \%$ in the elderly group. These differences were not statistically significant (ORR, $p=0.78$; DCR, $p=0.09$ ).

The median TTF for the XELOX + bevacizumab regimen was 7.1 months (95\% CI: 5.4 to 10.5) in the nonelderly group and 8.1 months (95\% CI: 5.4 to 14.0) in the elderly group ( $=0.838$ ) (Figure 2). In addition, the median TTF for the XELOX regimen was 2.8 months (95\%: CI 1.5 to 3.8) and 3.2 months (95\% CI: 0.2 to 4.8 ) in the non-elderly and elderly groups, respectively $(\mathrm{p}=0.847)$ (Figure 3$)$.

\subsection{Safety}

Safety was evaluated in all patients who participated in this study. The incidence of primary toxic effects is summarized in Table 3 and Table 4 as the maximum grade per patient. The majority of treatment-related adverse events were mild to moderate in intensity.

\section{Table 2. Best response to first line treatment according to RECIST criteria.}

\begin{tabular}{cccccccccc}
\hline & \multicolumn{4}{c}{ XELOX + BEV regimen } & \multicolumn{3}{c}{ XELOX regimen } \\
\hline & $<70$ Years $(\mathrm{n}=26)$ & \multicolumn{2}{c}{$\geq 70$ Years $(\mathrm{n}=20)$} & \multicolumn{2}{c}{$<$ Years $(\mathrm{n}=19)$} & \multicolumn{2}{c}{$\geq 70$ Years $(\mathrm{n}=14)$} \\
\hline & $\mathrm{n}$ & $\%$ & $\mathrm{n}$ & $\%$ & $\mathrm{n}$ & $\%$ & $\mathrm{n}$ & $\%$ \\
\hline Complete response & 2 & $(7.7 \%)$ & 1 & $(5.0 \%)$ & 0 & $(0.0 \%)$ & 0 & $(0.0 \%)$ \\
Partial response & 6 & $(23.1 \%)$ & 7 & $(35.0 \%)$ & 3 & $(15.8 \%)$ & 2 & $(14.3 \%)$ \\
Stable disease & 11 & $(42.3 \%)$ & 10 & $(50.0 \%)$ & 7 & $(36.8 \%)$ & 2 & $(14.3 \%)$ \\
Progressive disease & 0 & $(0.0 \%)$ & 2 & $(10.0 \%)$ & 2 & $(10.5 \%)$ & 3 & $(21.4 \%)$ \\
Not evaluated & 7 & $(26.9 \%)$ & 0 & $(0.0 \%)$ & 7 & $(36.8 \%)$ & 7 & $(50.0 \%)$ \\
\hline
\end{tabular}




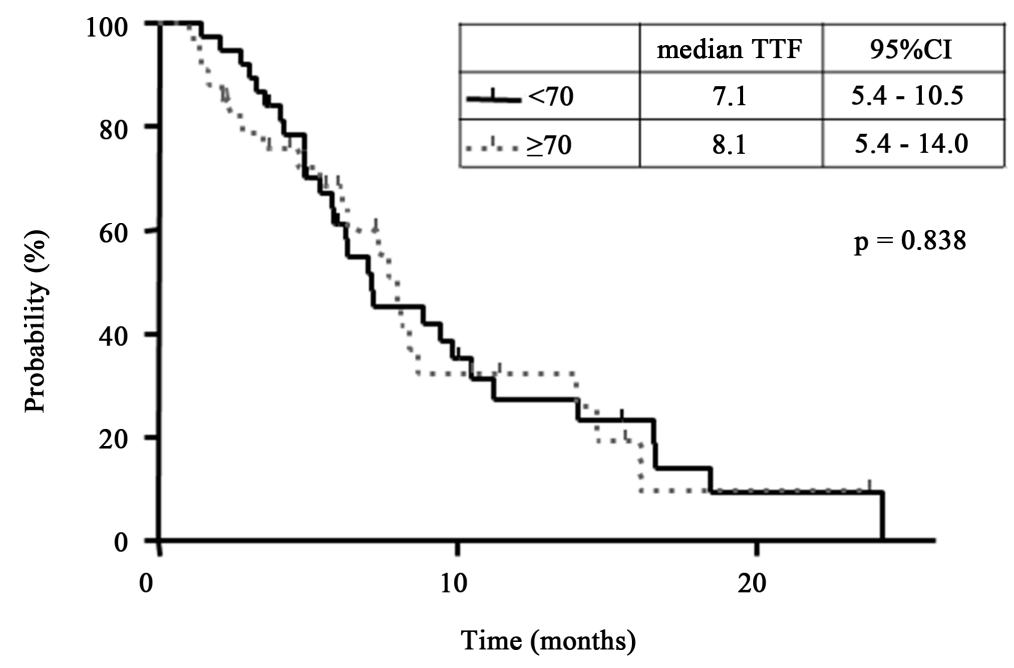

Figure 2. Kaplan-Meier curves of the time to treatment failure (TTF) in the XELOX + bevacizumab group. The median TTF was 7.1 months and 8.1 months in the non-elderly group $(-)$ and elderly group (…..), respectively.

Table 3. Major adverse events of XELOX with bevacizumab treatment in all treatment lines $(\mathrm{n}=78)$.

\begin{tabular}{|c|c|c|c|c|c|c|c|c|c|}
\hline & \multirow{2}{*}{\multicolumn{2}{|c|}{$\begin{array}{c}<70 \text { Years }(\mathrm{n}=42) \\
\text { Grade } 1-2\end{array}$}} & \multicolumn{6}{|c|}{$\geq 70$ Years $(\mathrm{n}=36)$} & \multirow[t]{3}{*}{ p Values } \\
\hline & & & \multicolumn{2}{|c|}{ Grade $\geq 3$} & \multicolumn{2}{|c|}{ Grade 1 - 2} & \multicolumn{2}{|c|}{ Grade $\geq 3$} & \\
\hline & $\mathrm{n}$ & (\%) & $\mathrm{n}$ & $(\%)$ & $\mathrm{n}$ & (\%) & $\mathrm{n}$ & $(\%)$ & \\
\hline \multicolumn{10}{|l|}{$\begin{array}{l}\text { Related to capecitabine } \\
\text { and oxaliplatin }\end{array}$} \\
\hline Leukocytopenia & 4 & $(9.5 \%)$ & 6 & $(14.3 \%)$ & 3 & $(8.3 \%)$ & 2 & $(5.6 \%)$ & 0.409 \\
\hline Thrombocytopenia & 10 & $(23.8 \%)$ & 0 & $(0.0 \%)$ & 5 & $(13.9 \%)$ & 0 & $(0.0 \%)$ & 0.042 \\
\hline & \multicolumn{2}{|c|}{ Grade 1} & \multicolumn{2}{|c|}{ Grade $\geq 2$} & \multicolumn{2}{|c|}{ Grade 1} & \multicolumn{2}{|c|}{ Grade $\geq 2$} & \\
\hline Nausea and vomiting & 5 & $(11.9 \%)$ & 3 & $(7.1 \%)$ & 3 & $(8.3 \%)$ & 3 & $(8.3 \%)$ & 0.597 \\
\hline Fatigue & 3 & $(7.1 \%)$ & 1 & $(2.4 \%)$ & 4 & $(11.1 \%)$ & 1 & $(2.8 \%)$ & 0.288 \\
\hline Aphtha & 0 & $(0.0 \%)$ & 0 & $(0.0 \%)$ & 3 & $(8.3 \%)$ & 0 & $(0.0 \%)$ & 0.029 \\
\hline Diarrhea & 3 & $(7.1 \%)$ & 0 & $(0.0 \%)$ & 2 & $(5.6 \%)$ & 0 & $(0.0 \%)$ & 0.775 \\
\hline Hand-foot syndrome & 1 & $(2.4 \%)$ & 8 & $(19.0 \%)$ & 0 & $(0.0 \%)$ & 6 & $(16.7 \%)$ & 0.508 \\
\hline Peripheral neuropathy & 13 & (31.0\%) & 17 & $(40.5 \%)$ & 10 & $(27.8 \%)$ & 7 & $(19.4 \%)$ & 0.054 \\
\hline Gastrointestinal perforation & 0 & $(0.0 \%)$ & 0 & $(0.0 \%)$ & 0 & $(0.0 \%)$ & 0 & $(0.0 \%)$ & - \\
\hline Hemorrhage & 0 & $(0.0 \%)$ & 0 & $(0.0 \%)$ & 1 & $(2.8 \%)$ & 0 & $(0.0 \%)$ & 0.211 \\
\hline Hypertension & 1 & $(2.4 \%)$ & 4 & $(9.5 \%)$ & 1 & $(2.8 \%)$ & 7 & $(19.4 \%)$ & 0.446 \\
\hline Proteinuria & 0 & $(0.0 \%)$ & 0 & $(0.0 \%)$ & 0 & $(0.0 \%)$ & 0 & $(0.0 \%)$ & - \\
\hline Thromboembolism & 0 & $(0.0 \%)$ & 0 & $(0.0 \%)$ & 0 & $(0.0 \%)$ & 0 & $(0.0 \%)$ & - \\
\hline Wound dehiscence & 0 & $(0.0 \%)$ & 0 & $(0.0 \%)$ & 0 & $(0.0 \%)$ & 0 & $(0.0 \%)$ & - \\
\hline
\end{tabular}

The grade of adverse events was defined according to the CTCAE v4.0 guidelines. ${ }^{*}$ p values were calculated using Fisher's exact probability test. The values in parentheses are percentages of the raw totals. 


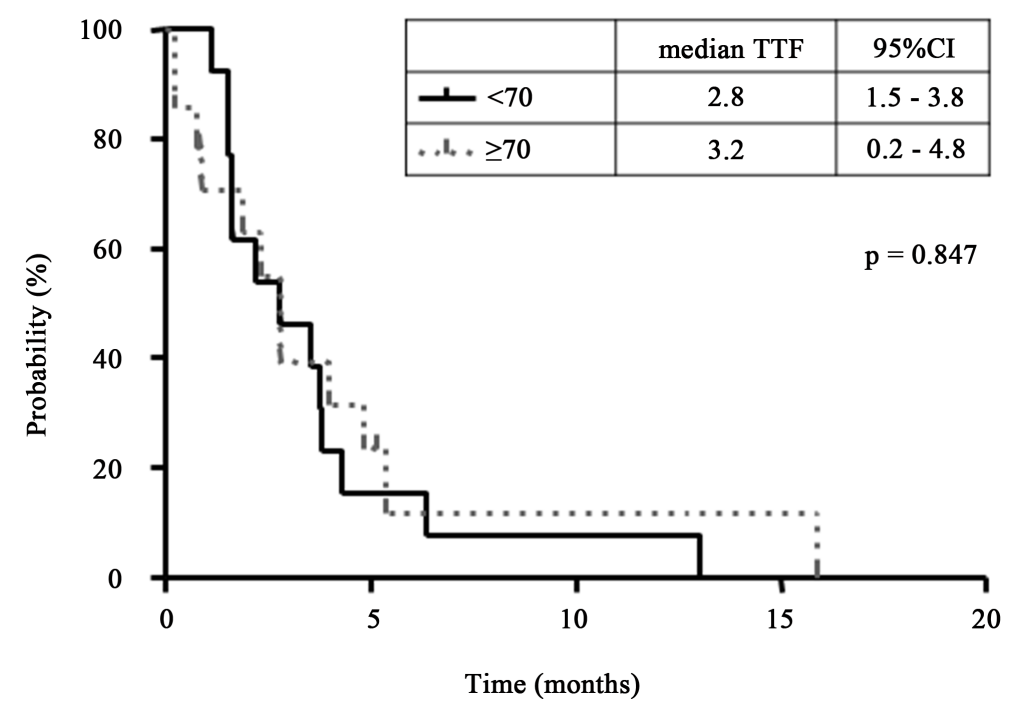

Figure 3. Kaplan-Meier curves of the TTF in the XELOX group. The median TTF was 2.8 months and 3.2 months in the non-elderly group $(-)$ and elderly group (…*), respectively.

Table 4. Major adverse events of XELOX treatment in all treatment lines $(n=29)$.

\begin{tabular}{|c|c|c|c|c|c|c|c|c|c|}
\hline & \multirow{2}{*}{\multicolumn{2}{|c|}{$\begin{array}{c}<70 \text { Years }(\mathrm{n}=13) \\
\text { Grade } 1 \text { - } 2\end{array}$}} & \multicolumn{6}{|c|}{$\geq 70$ Years $(n=16)$} & \multirow[t]{3}{*}{ p Values ${ }^{*}$} \\
\hline & & & & $\mathrm{de} \geq 3$ & & $1-2$ & & $\mathrm{de} \geq 3$ & \\
\hline & $\mathrm{n}$ & $(\%)$ & $\mathrm{n}$ & (\%) & $\mathrm{n}$ & (\%) & $\mathrm{n}$ & (\%) & \\
\hline \multicolumn{10}{|l|}{$\begin{array}{l}\text { Related to capecitabine } \\
\text { and oxaliplatin }\end{array}$} \\
\hline Leukocytopenia & 2 & $(15.4 \%)$ & 0 & $(0.0 \%)$ & 1 & $(6.3 \%)$ & 0 & $(0.0 \%)$ & 0.421 \\
\hline \multirow[t]{2}{*}{ Thrombocytopenia } & 2 & $(15.4 \%)$ & 0 & $(0.0 \%)$ & 2 & $(12.5 \%)$ & 0 & $(0.0 \%)$ & 0.823 \\
\hline & \multicolumn{2}{|c|}{ Grade 1} & \multicolumn{2}{|c|}{ Grade $\geq 2$} & \multicolumn{2}{|c|}{ Grade 1} & \multicolumn{2}{|c|}{ Grade $\geq 2$} & \\
\hline Nausea and vomiting & 2 & $(15.4 \%)$ & 0 & $(0.0 \%)$ & 1 & $(6.3 \%)$ & 1 & $(6.3 \%)$ & 0.411 \\
\hline Fatigue & 1 & $(7.7 \%)$ & 0 & $(0.0 \%)$ & 2 & $(12.5 \%)$ & 1 & $(6.3 \%)$ & 0.483 \\
\hline Aphtha & 0 & $(0.0 \%)$ & 0 & $(0.0 \%)$ & 0 & $(0.0 \%)$ & 0 & $(0.0 \%)$ & - \\
\hline Diarrhea & 1 & $(7.7 \%)$ & 0 & $(0.0 \%)$ & 1 & $(6.3 \%)$ & 0 & $(0.0 \%)$ & 0.879 \\
\hline Hand-foot syndrome & 0 & $(0.0 \%)$ & 3 & (23.1\%) & 0 & $(0.0 \%)$ & 3 & $(18.8 \%)$ & 0.775 \\
\hline Peripheral neuropathy & 6 & $(46.2 \%)$ & 1 & $(7.7 \%)$ & 1 & $(6.3 \%)$ & 1 & $(6.3 \%)$ & 0.031 \\
\hline
\end{tabular}

The grade of adverse events was defined according to the CTCAE v4.0 guidelines. ${ }^{*}$ p values were calculated using Fisher's exact probability test. The values in parentheses are percentages of the raw totals.

Although there was no statistically significant difference, non-elderly patients showed a high incidence of neurotoxicity $(71.5 \%)$ when compared to elderly patients $(47.2 \%)(p=0.054)$. In the XELOX + bevacizumab chemotherapy, severe neurotoxicity more than Grade 2 occurred in $40.5 \%$ of the non-elderly patients, being significantly higher than that observed in the elderly patients $(19.4 \%)(p=0.045)$. In addition, the incidence of neurotoxicity related with the XELOX treatment was significantly higher in the non-elderly group (53.8\%) than in the elderly group $(12.6 \%, \mathrm{p}=0.031)$. The common adverse events more than Grade 2 in the XELOX + bevacizumab treatment group were hand-foot syndrome (19.0\% in the non-elderly group and $16.7 \%$ in the elderly group; $\mathrm{p}=0.508$ ) and hypertension (9.5\% in the non-elderly group and $19.4 \%$ in the elderly group; $\mathrm{p}=0.446$ ). Severe diarrhea, nausea, vomiting, general fatigue and allergies were rarely observed. 


\section{Discussion}

In general, CRC occurs frequently in elderly people and intensive chemotherapy is required for unresectable disease. However, there are no sufficient data regarding the selection of chemotherapy regimens for elderly CRC patients because little number of elderly patients are eligible in clinical trials [11]. Therefore, we conducted a retrospective cohort study for investigating the actual situation of standard triplet chemotherapy plus molecular targeted drugs in elderly patients with unresectable CRC. In the present study, the 2 study groups, elderly and non-elderly groups, were nearly equal in number. The main finding of this study was that the TTF of the elderly patients $>70$ years of age was not different from that of the younger group, regardless of the use of bevacizumab. This finding indicates that older and younger patients could achieve an equivalent treatment benefits from intensive chemotherapy.

Although previous studies have reported that adding bevacizumab to chemotherapy has significant benefits for CRC patients [16] [17], some reports have shown that the benefits in elderly patients are reduced [18]. In this study, the median TTF for the XELOX + bevacizumab regimen was 7.1 months in the non-elderly group and 8.1 months in the elderly group, indicating that there is a similar benefit in adding bevacizumab to chemotherapy in all age groups. On the other hand, the TTF was significantly shorter in the XELOX regimen than in the XELOX plus bevacizumab regimen in both younger and elderly patient groups. In this study, each participating physician decided whether to add bevacizumab to the chemotherapy regimen. Therefore, the patients who did not receive bevacizumab may have had some contraindication for bevacizumab, such as thrombosis, hypertension, proteinuria, epistaxis and so on, as previously described [5]. At any rate, the patients who received bevacizumab treatment tended to have the benefit in terms of TTF in both two age groups.

Generally, the pharmacokinetics of a drug deteriorates in the elderly due to organ dysfunction associated with aging [19] [20]. There are some reports that the incidence of adverse events tends to increase with age [21] [22]. Therefore, dose reductions and treatment delays are usually performed in elderly patient because of safety concerns. However, all elderly patients were received same dose of younger patients in our study. In addition, the elderly and non-elderly patients did not differ in the incidence of adverse events and all adverse events were controllable even in the elderly patients. The complete administration of drugs as planned, including 5-FU/LV, irinotecan and oxaliplatin, prolongs survival in patients with colon cancer. Therefore, it is important that safe and effective regimens are used in elderly patients as first-line chemotherapy.

Although there was no statistical difference, the incidence of severe neuropathy was higher in the XELOX + bevacizumab group (42.9\%) than in the XELOX group (3.6\%) in our 56 patients with peripheral neuropathy. The XELOX + bevacizumab group, furthermore, the incidence of peripheral neuropathy was significantly higher in the non-elderly patients (40.5\%) than in the elderly patients (19.4\%) in our study. All patients received same planned administration of preventing drugs. The reason why this incidence was lower in the elderly patients is unclear. Therefore, further studies and research are needed.

Many CRC patients have to withdraw from oxaliplatin-containing regimens due to severe dysesthesia and cumulative peripheral sensory neuropathy. This neuropathy persists for a long time after withdrawing oxaliplatin treatment. There are some reports that a stop-and-go strategy can reduce the development of sensory neuropathy and has equivalent efficacy in comparison to the continuance of oxaliplatin-containing regimens until disease progression or the development of unacceptable toxicities [23]. Therefore, we are studying the safety and efficacy of a stop-and-go strategy with a XELOX + bevacizumab regimen in a Phase II study.

A previous study reported the benefits of adding bevacizumab to chemotherapy in medically fit patients $>65$ years of age, with no increase in the risk of adverse events [16]. Although we defined an elderly patient as a patient $\geq 70$ years of age in our study, the similar tendency was observed. Intensive chemotherapy can be administered in elderly patients with careful selection of patients and monitoring of adverse events.

In conclusion, the XELOX chemotherapy with or without bevacizumab has equivalent efficacy in the treatment of elderly and non-elderly patients with unresectable CRC, without increasing the incidence of adverse events in the elderly. Carefully selecting elderly patients and managing adverse events are required to administer combination chemotherapy in this patient population.

\section{Conflict-of-Interest Notification Field}

The authors declare that they have no conflict of interests. 


\section{References}

[1] Golfinopoulos, V., Salanti, G., Pavlidis, N. and Ioannidis, J.P. (2007) Survival and Disease-Progression Benefits with Treatment Regimens for Advanced Colorectal Cancer: A Meta-Analysis. The Lancet Oncology, 8, 898-911. http://dx.doi.org/10.1016/S1470-2045(07)70281-4

[2] Rothenberg, M.L., Cox, J.V., Butts, C., Navarro, M., Goel, R., Gollins, S., Siu, L.L., Laguerre, S. and Cunningham, D. (2008) Capecitabine plus Oxaliplatin (XELOX) versus 5-Fluorouracil/Folinic Acid plus Oxaliplatin (FOLFOX-4) as Second-Line Therapy in Metastatic Colorectal Cancer: A Randomized Phase III Noninferiority Study. Annals of Oncology, 19, 1720-1726. http://dx.doi.org/10.1093/annonc/mdn370

[3] Saltz, L.B., Clarke, S., Diaz-Rubio, E., Scheithauer, W., Figer, A., Wong, R., Koski, S., Lichinitser, M., Yang, T.S., Rivera, F., Couture, F., Sirzen, F. and Cassidy, J. (2008) Bevacizumab in Combination with Oxaliplatin-Based Chemotherapy as First-Line Therapy in Metastatic Colorectal Cancer: A Randomized Phase III Study. Journal of Clinical Oncology, 26, 2013-2019. http://dx.doi.org/10.1200/JCO.2007.14.9930

[4] Kabbinavar, F., Hurwitz, H.I., Fehrenbacher, L., Meropol, N.J., Novotny, W.F., Lieberman, G., Griffing, S. and Bergsland, E. (2003) Phase II, Randomized Trial Comparing Bevacizumab plus Fluorouracil (FU)/Leucovorin (LV) with FU/LV Alone in Patients with Metastatic Colorectal Cancer. Journal of Clinical Oncology, 21, 60-65. http://dx.doi.org/10.1200/JCO.2003.10.066

[5] Hurwitz, H., Fehrenbacher, L., Novotny, W., Cartwright, T., Hainsworth, J., Heim, W., Berlin, J., Baron, A., Griffing, S., Holmgren, E., Ferrara, N., Fyfe, G., Rogers, B., Ross, R. and Kabbinavar, F. (2004) Bevacizumab plus Irinotecan, Fluorouracil, and Leucovorin for Metastatic Colorectal Cancer. The New England Journal of Medicine, 350, 23352342. http://dx.doi.org/10.1056/NEJMoa032691

[6] Argyriou, A.A., Polychronopoulos, P., Iconomou, G., Chroni, E. and Kalofonos, H.P. (2008) A Review on OxaliplatinInduced Peripheral Nerve Damage. Cancer Treatment Reviews, 34, 368-377. http://dx.doi.org/10.1016/j.ctrv.2008.01.003

[7] Scappaticci, F.A., Skillings, J.R., Holden, S.N., Gerber, H.P., Miller, K., Kabbinavar, F., Bergsland, E., Ngai, J., Holmgren, E., Wang, J. and Hurwitz, H. (2007) Arterial Thromboembolic Events in Patients with Metastatic Carcinoma Treated with Chemotherapy and Bevacizumab. Journal of the National Cancer Institute, 99, 1232-1239. http://dx.doi.org/10.1093/jnci/djm086

[8] Kohne, C.H., Grothey, A., Bokemeyer, C., Bontke, N. and Aapro, M. (2001) Chemotherapy in Elderly Patients with Colorectal Cancer. Annals of Oncology, 12, 435-442. http://dx.doi.org/10.1023/A:1011170808734

[9] Folprecht, G., Cunningham, D., Ross, P., Glimelius, B., Di Costanzo, F., Wils, J., Scheithauer, W., Rougier, P., Aranda, E., Hecker, H. and Kohne, C.H. (2004) Efficacy of 5-Fluorouracil-Based Chemotherapy in Elderly Patients with Metastatic Colorectal Cancer: A Pooled Analysis of Clinical Trials. Annals of Oncology, 15, 1330-1338. http://dx.doi.org/10.1093/annonc/mdh344

[10] Yamamoto, T., Katano, K., Sugimoto, S., Kanazawa, A., Hira, E., Takeda, H., Sato, Y., Yamashiro, Y., Tajima, Y. and Ikeguchi, M. (2014) Multicenter Analysis of mFOLFOX6 with Oxaliplatin Stop-and-Go Strategy Using Oral UracilTegafur with Leucovorin for Unresectable Colorectal Cancer in Elderly Patients. Journal of Cancer Therapy, 5, 146153. http://dx.doi.org/10.4236/jct.2014.52018

[11] Hutchins, L.F., Unger, J.M., Crowley, J.J., Coltman Jr., C.A. and Albain, K.S. (1999) Underrepresentation of Patients 65 Years of Age or Older in Cancer-Treatment Trials. New England Journal of Medicine, 341, 2061-2067. http://dx.doi.org/10.1056/NEJM199912303412706

[12] Venderbosch, S., Doornebal, J., Teerenstra, S., Lemmens, W., Punt, C.J. and Koopman, M. (2012) Outcome of First Line Systemic Treatment in Elderly Compared to Younger Patients with Metastatic Colorectal Cancer: A Retrospective Analysis of the CAIRO and CAIRO2 Studies of the Dutch Colorectal Cancer Group (DCCG). Acta Oncologica, 51, 831-839. http://dx.doi.org/10.3109/0284186X.2012.699193

[13] Therasse, P., Arbuck, S.G., Eisenhauer, E.A., Wanders, J., Kaplan, R.S., Rubinstein, L., Verweij, J., Van Glabbeke, M., van Oosterom, A.T., Christian, M.C. and Gwyther, S.G. (2000) New Guidelines to Evaluate the Response to Treatment in Solid Tumors. European Organization for Research and Treatment of Cancer, National Cancer Institute of the United States, National Cancer Institute of Canada. Journal of the National Cancer Institute, 92, 205-216. http://dx.doi.org/10.1093/jnci/92.3.205

[14] Chen, A.P., Setser, A., Anadkat, M.J., Cotliar, J., Olsen, E.A., Garden, B.C. and Lacouture, M.E. (2012) Grading Dermatologic Adverse Events of Cancer Treatments: The Common Terminology Criteria for Adverse Events Version 4.0. Journal of the American Academy of Dermatology, 67, 1025-1039. http://dx.doi.org/10.1016/j.jaad.2012.02.010

[15] Eisenhauer, E.A., Therasse, P., Bogaerts, J., Schwartz, L.H., Sargent, D., Ford, R., Dancey, J., Arbuck, S., Gwyther, S., Mooney, M., Rubinstein, L., Shankar, L., Dodd, L., Kaplan, R., Lacombe, D. and Verweij, J. (2009) New Response Evaluation Criteria in Solid Tumours: Revised RECIST Guideline. European Journal of Cancer, 45, 228-247. http://dx.doi.org/10.1016/j.ejca.2008.10.026 
[16] Kabbinavar, F.F., Hurwitz, H.I., Yi, J., Sarkar, S. and Rosen, O. (2009) Addition of Bevacizumab to FluorouracilBased First-Line Treatment of Metastatic Colorectal Cancer: Pooled Analysis of Cohorts of Older Patients from Two Randomized Clinical Trials. Journal of Clinical Oncology, 27, 199-205. http://dx.doi.org/10.1200/JCO.2008.17.7931

[17] Cassidy, J., Saltz, L.B., Giantonio, B.J., Kabbinavar, F.F., Hurwitz, H.I. and Rohr, U.P. (2010) Effect of Bevacizumab in Older Patients with Metastatic Colorectal Cancer: Pooled Analysis of Four Randomized Studies. Journal of Cancer Research and Clinical Oncology, 136, 737-743. http://dx.doi.org/10.1007/s00432-009-0712-3

[18] Kozloff, M.F., Berlin, J., Flynn, P.J., Kabbinavar, F., Ashby, M., Dong, W., Sing, A.P. and Grothey, A. (2010) Clinical Outcomes in Elderly Patients with Metastatic Colorectal Cancer Receiving Bevacizumab and Chemotherapy: Results from the BRiTE Observational Cohort Study. Oncology, 78, 329-339. http://dx.doi.org/10.1159/000320222

[19] Greenblatt, D.J., Sellers, E.M. and Shader, R.I. (1982) Drug Disposition in Old Age. New England Journal of Medicine, 306, 1081-1088. http://dx.doi.org/10.1056/NEJM198205063061804

[20] Montamat, S.C., Cusack, B.J. and Vestal, R.E. (1989) Management of Drug Therapy in the Elderly. New England Journal of Medicine, 321, 303-309. http://dx.doi.org/10.1056/NEJM198908033210507

[21] Silverstein, M.D., Heit, J.A., Mohr, D.N., Petterson, T.M., O’Fallon, W.M. and Melton, L.J. (1998) Trends in the Incidence of Deep Vein Thrombosis and Pulmonary Embolism: A 25-Year Population-Based Study. JAMA Internal Medicine, 158, 585-593. http://dx.doi.org/10.1001/archinte.158.6.585

[22] Goldberg, R.M., Tabah-Fisch, I., Bleiberg, H., de Gramont, A., Tournigand, C., Andre, T., Rothenberg, M.L., Green, E. and Sargent, D.J. (2006) Pooled Analysis of Safety and Efficacy of Oxaliplatin plus Fluorouracil/Leucovorin Administered Bimonthly in Elderly Patients with Colorectal Cancer. Journal of Clinical Oncology, 24, 4085-4091. http://dx.doi.org/10.1200/JCO.2006.06.9039

[23] Tournigand, C., Cervantes, A., Figer, A., Lledo, G., Flesch, M., Buyse, M., Mineur, L., Carola, E., Etienne, P.L., Rivera, F., Chirivella, I., Perez-Staub, N., Louvet, C., André, T., Tabah-Fisch, I. and de Gramont, A. (2006) OPTIMOX1: A Randomized Study of FOLFOX4 or FOLFOX7 with Oxaliplatin in a Stop-and-Go Fashion in Advanced Colorectal Cancer-A GERCOR Study. Journal of Clinical Oncology, 24, 394-400. http://dx.doi.org/10.1200/JCO.2005.03.0106

\section{List of Abbreviations}

XELOX: capecitabine + oxaliplatin + leucovorin combined chemotherapy;

TTF: median time to treat failure;

ORR: overall response rate;

DCR: disease control rate;

CRC: colorectal cancer. 
Scientific Research Publishing (SCIRP) is one of the largest Open Access journal publishers. It is currently publishing more than 200 open access, online, peer-reviewed journals covering a wide range of academic disciplines. SCIRP serves the worldwide academic communities and contributes to the progress and application of science with its publication.

Other selected journals from SCIRP are listed as below. Submit your manuscript to us via either submit@scirp.org or Online Submission Portal.
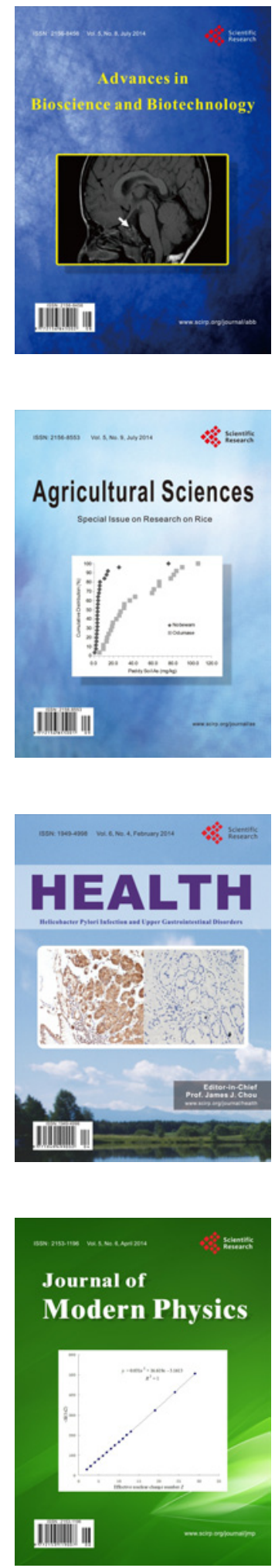
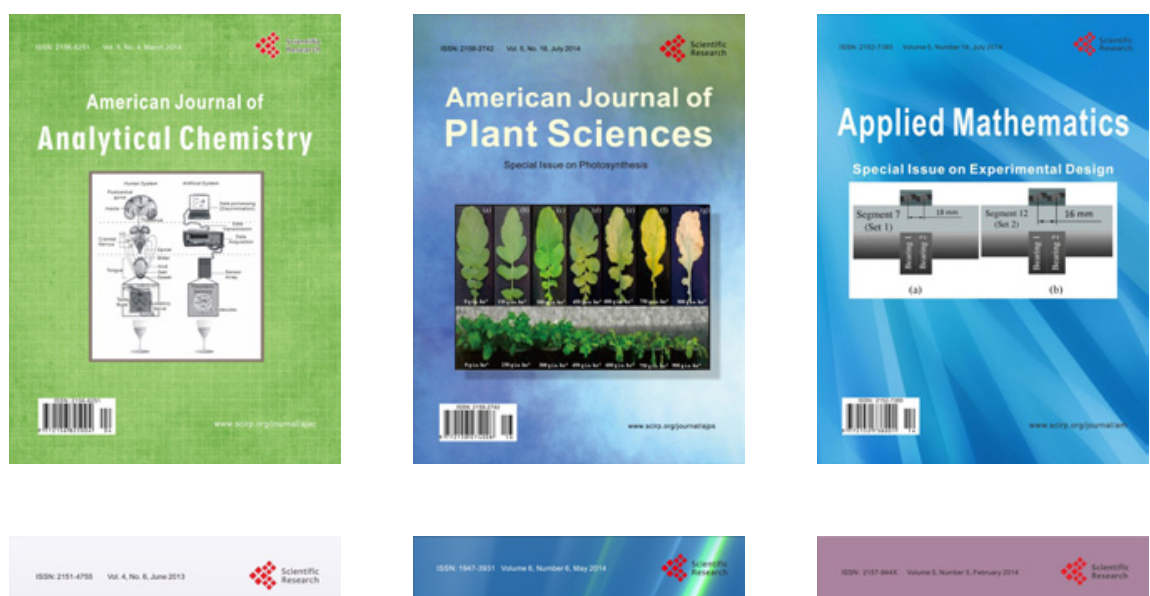

Creative Education
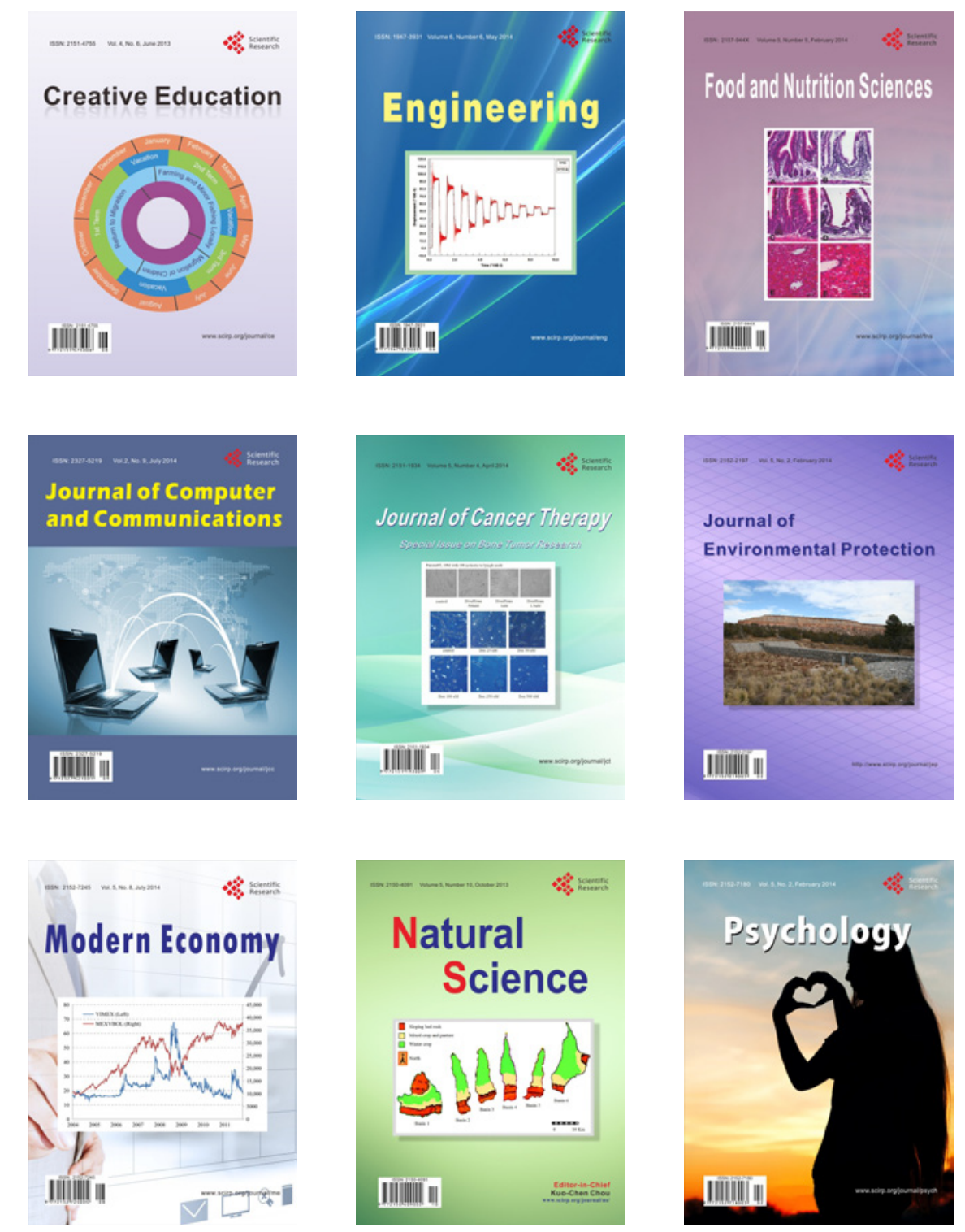